\title{
Coupled Modeling of a Directly Heated Tubular Solar Receiver for Supercritical Carbon Dioxide Brayton Cycle: Optical and Thermal-Fluid Evaluation
}

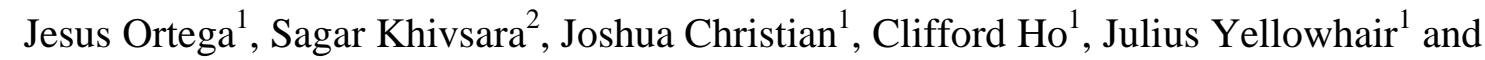 \\ Pradip Dutta ${ }^{2}$ \\ ${ }^{1}$ Sandia National Laboratories, Concentrating Solar Technologies Department, Albuquerque, NM \\ 87185-1127, USA, (505)-284-4208, jdorte@sandia.gov \\ ${ }^{2}$ Indian Institute of Science, Dept. of Mechanical Engineering Bangalore, KA 560012, India.
}

\section{ABSTRACT}

Single phase performance and appealing thermo-physical properties make supercritical carbon dioxide $\left(\mathrm{s}-\mathrm{CO}_{2}\right)$ a good heat transfer fluid candidate for concentrating solar power (CSP) technologies. The development of a solar receiver capable of delivering s$\mathrm{CO}_{2}$ at outlet temperatures $\sim 973 \mathrm{~K}$ is required in order to merge CSP and s- $\mathrm{CO}_{2}$ Brayton cycle technologies. A coupled optical and thermal-fluid modeling effort for a tubular receiver is undertaken to evaluate the direct tubular s- $\mathrm{CO}_{2}$ receiver's thermal performance when exposed to a concentrated solar power input of $\sim 0.3-0.5 \mathrm{MW}$. Ray tracing, using SolTrace, is performed to determine the heat flux profiles on the receiver and computational fluid dynamics (CFD) determines the thermal performance of the receiver under the specified heating conditions. An in-house MATLAB code is developed to couple SolTrace and ANSYS Fluent. CFD modeling is performed using ANSYS Fluent to predict the thermal performance of the receiver by evaluating radiation and convection heat loss mechanisms. Understanding the effects of variation in heliostat aiming strategy and flow configurations on the thermal performance of the receiver was achieved through parametric analyses. A receiver thermal efficiency $\sim 85 \%$ was predicted and the surface temperatures were observed to be within the allowable limit for the materials under consideration.

Keywords: Concentrating solar, receiver, solar thermal, solar absorption 


\section{INTRODUCTION}

Possible use of supercritical cycles for power generation has been a topic of research since the 1960 's $[1,2]$. Supercritical carbon dioxide $\left(\mathrm{s}-\mathrm{CO}_{2}\right)$ has the potential to become the working fluid for a Brayton power cycles since it has been found viable to adapt to nuclear energy applications [3, 4]. Garg et al. have performed detailed irreversibility analysis of transcritical, subcritical and supercritical $\mathrm{CO}_{2}$ Brayton cycles for concentrated solar power [5]. Also, the dynamics of $\mathrm{s}-\mathrm{CO}_{2}$ based power conversion systems using CSP technologies have been investigated by Singh et al. [6].

Thanks to the favorable heat transfer properties that $\mathrm{s}-\mathrm{CO}_{2}$ possesses, its use as a working fluid provides the benefit of having a solar receiver with a smaller footprint, which can result in low heat losses and a low capital cost. These features make s- $\mathrm{CO}_{2}$ systems more energy-dense and they require lower mass flow rates compared to other heat transfer fluids. For example, at turbine inlet conditions for a s-CO $\mathrm{CO}_{2}$ Brayton cycle (15 MPa, $\left.1000 \mathrm{~K}\right)$, the density of s- $\mathrm{CO}_{2}$ is $\sim 11$ times the density of air in an air-Brayton cycle $(\sim 0.4 \mathrm{MPa}, 2000 \mathrm{~K})$, while the corresponding enthalpy of s- $\mathrm{CO}_{2}$ is about $53 \%$ of the value for air [7].

In order to develop an efficient $\mathrm{s}-\mathrm{CO}_{2}$ based CSP plant; there is a need to develop receivers which can endure a high operating pressure and high fluid temperature. An overview of existing receiver designs and past experiences is presented by Ho and Iverson, in which a theoretical maximum receiver efficiency of $80-85 \%$ is illustrated [8]. A recent design for a high temperature gas tubular receiver was demonstrated by DLR at Plataforma Solar De Almeria to have a receiver efficiency of $43 \%$ [8]. A review of demonstrations of volumetric receiver configurations is provided by Marin [9]. Although volumetric receivers have been successful in dispensing working fluid at temperatures above $1000 \mathrm{~K}$ and at efficiencies greater than $75 \%$, the problem of sealing and manufacturing of high pressure window poses a major engineering challenge. Problems of unstable flow and local overheating in volumetric 
1 absorbers have been studied by Becker et al. and Kribus et al., respectively [10, 11]. In light

2 of the practical problems discussed above, a tubular receiver seems to be the best alternative for direct heating of s- $\mathrm{CO}_{2}$ in a pressurized environment.

In this work, a direct tubular receiver using s- $\mathrm{CO}_{2}$ as the heat transfer fluid has been

\section{MATERIAL CONSIDERATIONS}

Dostal et al. describe possible s- $\mathrm{CO}_{2}$ conditions which can yield $50 \%$ thermodynamic cycle efficiency [12]. From those conditions, an operating pressure of $20 \mathrm{MPa}$ and an outlet temperature of $973 \mathrm{~K}$ are required for the receiver to achieve the prescribed cycle efficiency.

In a complementary work, the results of a structural and creep-fatigue analysis performed using analytical and numerical methods to select the optimal material and dimensions of the tubes of tubular receiver are presented. The material selected for this work is Inconel 625, since it displays outstanding allowable stress levels throughout the required temperature range. Fig. 1 shows the footprint of the illuminated receiver; tubes with outside diameter of $12.5 \mathrm{~mm}$ and wall thickness of $2.1 \mathrm{~mm}$ were selected.

\section{MODELING}

A coupled optical-thermal-fluid model was developed using SolTrace and ANSYS Fluent to evaluate the optical and thermal performance of the direct tubular receiver using optical ray-tracing and computational fluid dynamics (CFD). The results of the ray-trace analysis were coupled to ANSYS Fluent using the methodology described by Ortega et al., as a boundary condition [13]. 


\section{3.1. Geometry}

The simplified receiver geometry, shown in Fig. 1, consists of 80 straight parallel

tubes, each of length $1 \mathrm{~m}$, outside diameter of $12.5 \mathrm{~mm}$ and wall thickness of $2.1 \mathrm{~mm}$. Using

80 tubes is intended to maintain an aperture of $\sim 1 \mathrm{~m}^{2}$. Ortega et al., investigated the effect of

5 having staggered tube arrangements and showed no favorable increase in the receiver

6 efficiency, since it required a more complex flow distribution through the receiver [14]. The

780 tubes are divided into groups of 20. As shown in Fig. 2, these 20 tubes will form a single panel which consists of tubes connected to headers, at the top and bottom, to evenly distribute the s-CO $\mathrm{CO}_{2}$ flow. Fig. 2 also shows the complete receiver geometry which is made out of 4 panels and will be used to generate several flow patterns which could lead to high receiver efficiencies.

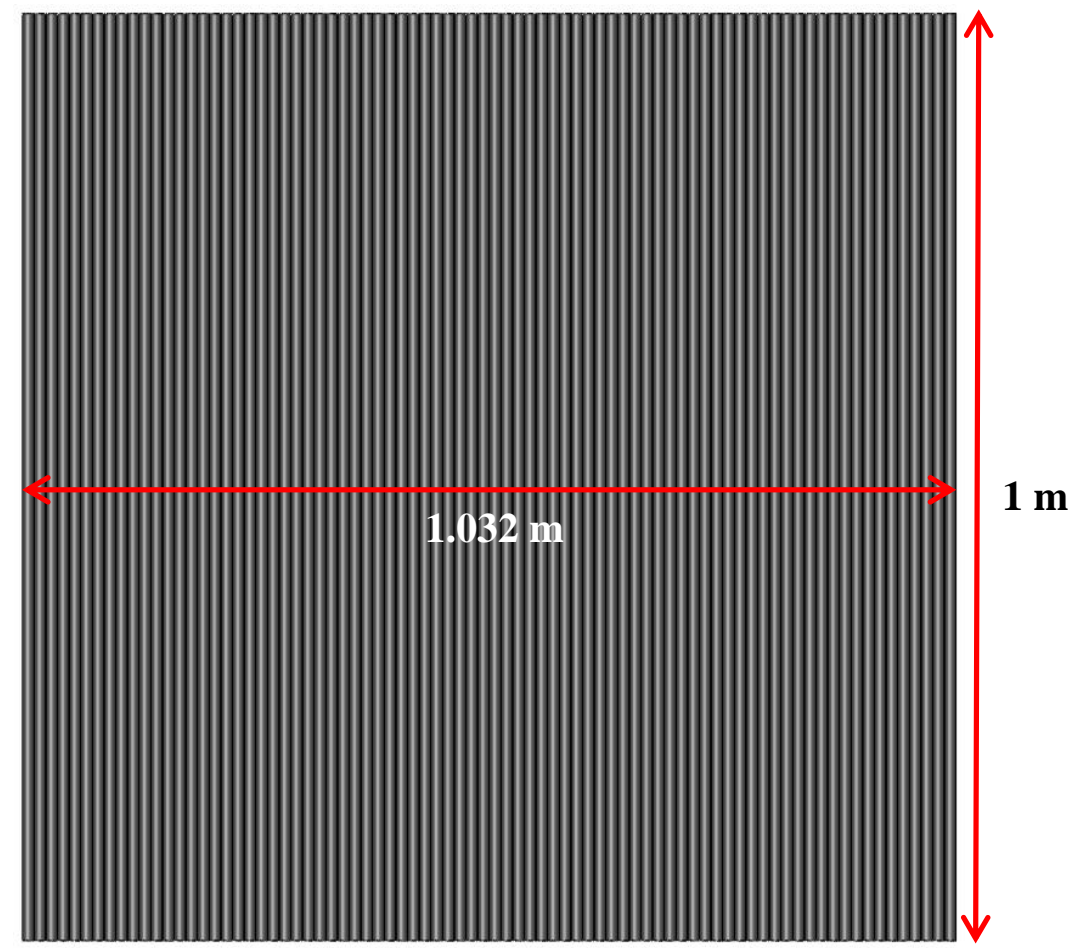
mm gaps for thermal expansion allowance. 


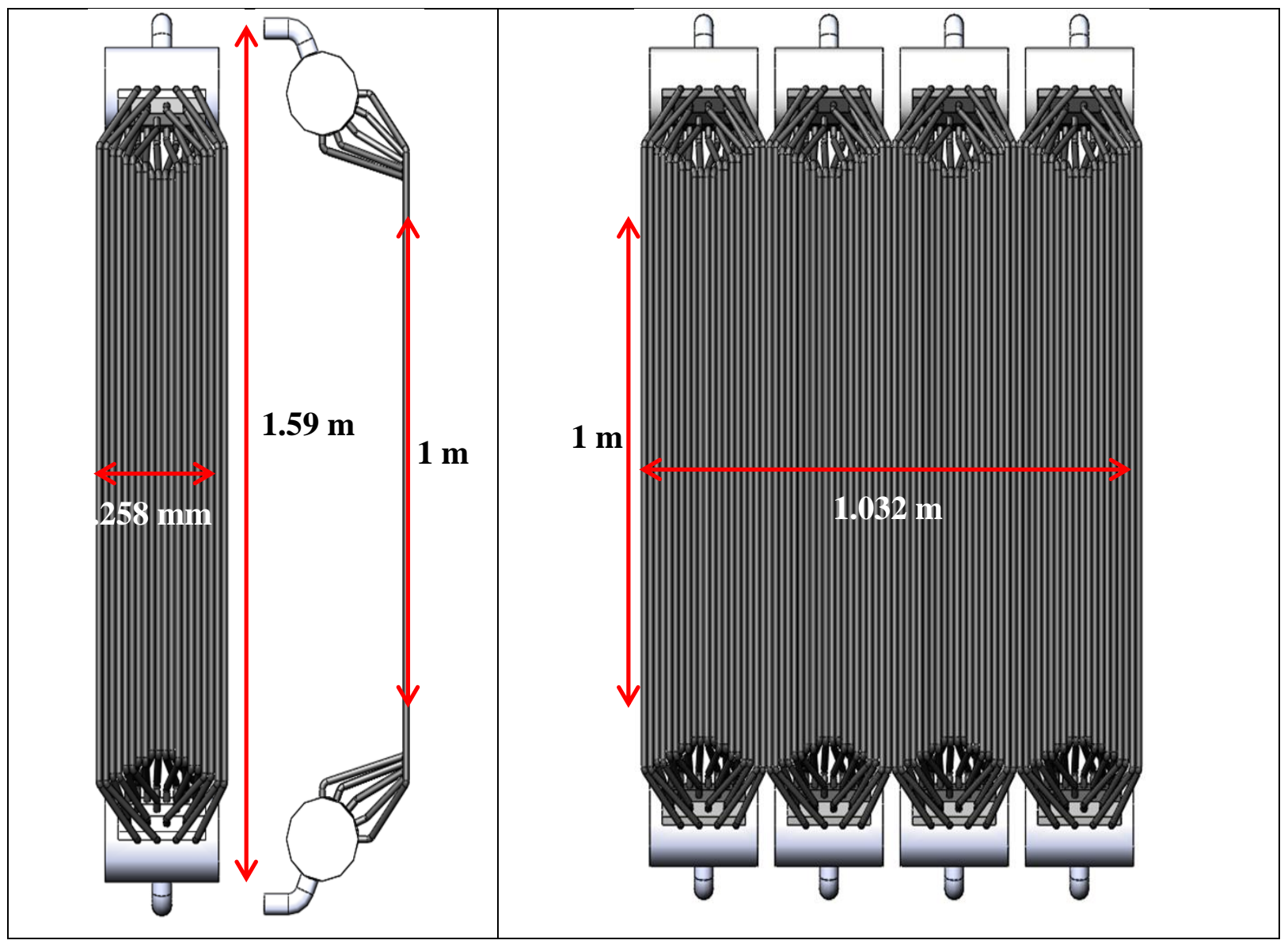

Figure 2. Left: Dimensions and connectivity of tubes to the top and bottom headers Right: Four panels with 20 tubes each comform the receiver to be analyzed.

\subsection{Optical Ray-Tracing Modeling}

Fig. 3 shows the heliostat field from the NSTTF modeled in SolTrace, along with the receiver geometries mentioned in the previous subsection. SolTrace is an optical modeling software developed by National Renewable Energy Laboratory (NREL), which uses the Monte-Carlo Ray tracing methodology for prediction of intensity distribution of intersections on a surface $[15,16]$.

Due to the size of the receiver considered, the amount of irradiance spillage is not considered for the calculation of effective solar absorptance which is calculated as:

$$
\eta_{\mathrm{opt}}=\frac{\dot{Q}_{\text {surf }}}{\dot{Q}_{\text {in }}}
$$

Where $\eta_{\text {opt }}$ the optical efficiency is the effective absorptance of the receiver $\dot{Q}_{s u r f}$ is the power absorbed by the receiver surface and $\dot{Q}_{i n}$ is the incident power on the receiver surface. 

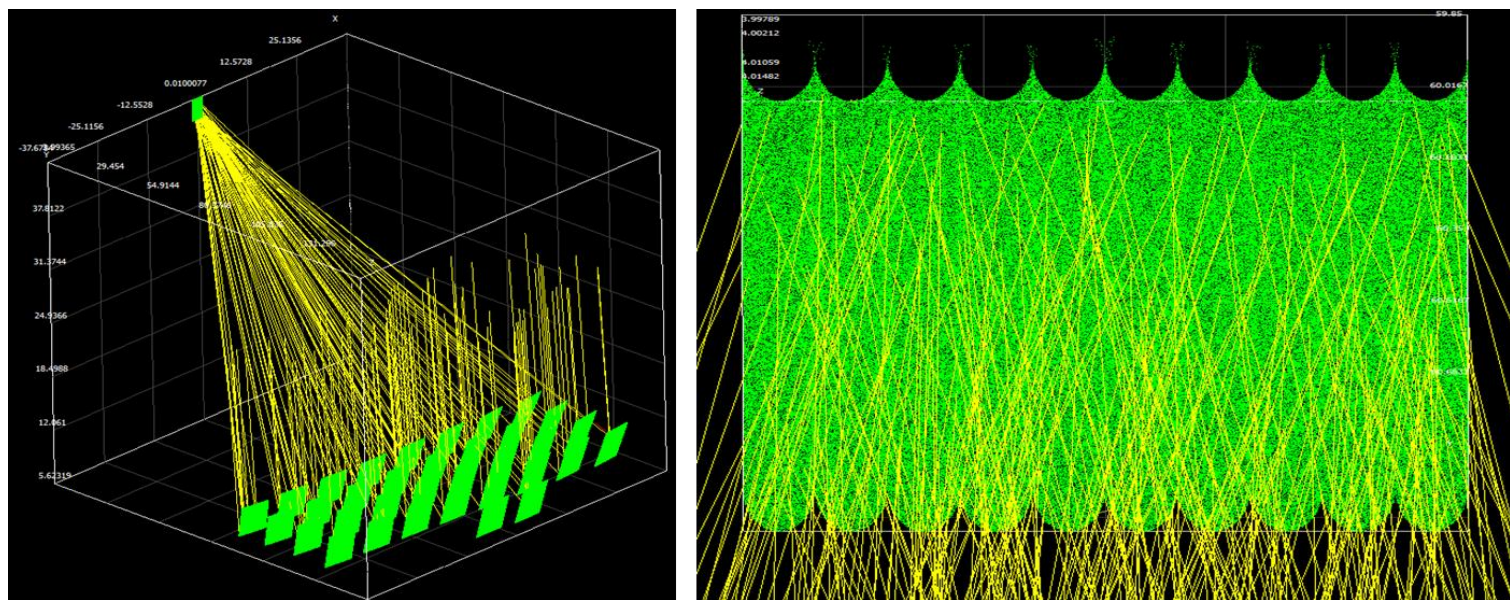

Figure 3. Left: Ray-trace analysis performed using the NSTTF heliostat field. The vertical rays represent the random rays emulating the sun. Right: Ray intersections on 10 tubes of the receiver surface.

Fig. 4 shows the four aiming strategies selected to investigate the uniformity of the

heat flux distributions on the tube surfaces. The aim-points were generated by assuming a virtual intercept divided into $(n+1)^{2}$ sections with $n$ being the number of aim-points required. Three virtual apertures of $1 \mathrm{~m}^{2}, 4 \mathrm{~m}^{2}$ and $9 \mathrm{~m}^{2}$ were considered and the aim-point locations were considered as shown in Fig. 4.
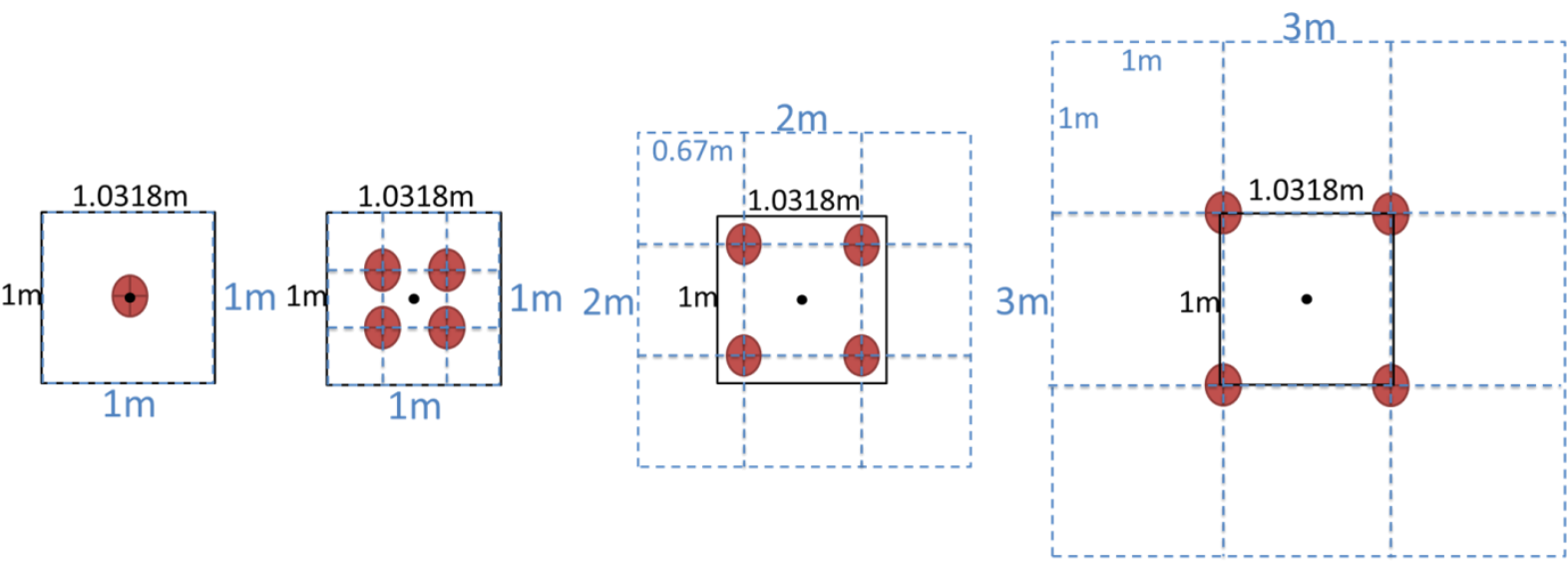

Figure 4. Four aiming strategies investigated. The dots represent the location of the aim-points with respect to the receiver aperture. The virtual intercept is represented by dotted lines while the real aperture is in solid black lines. 


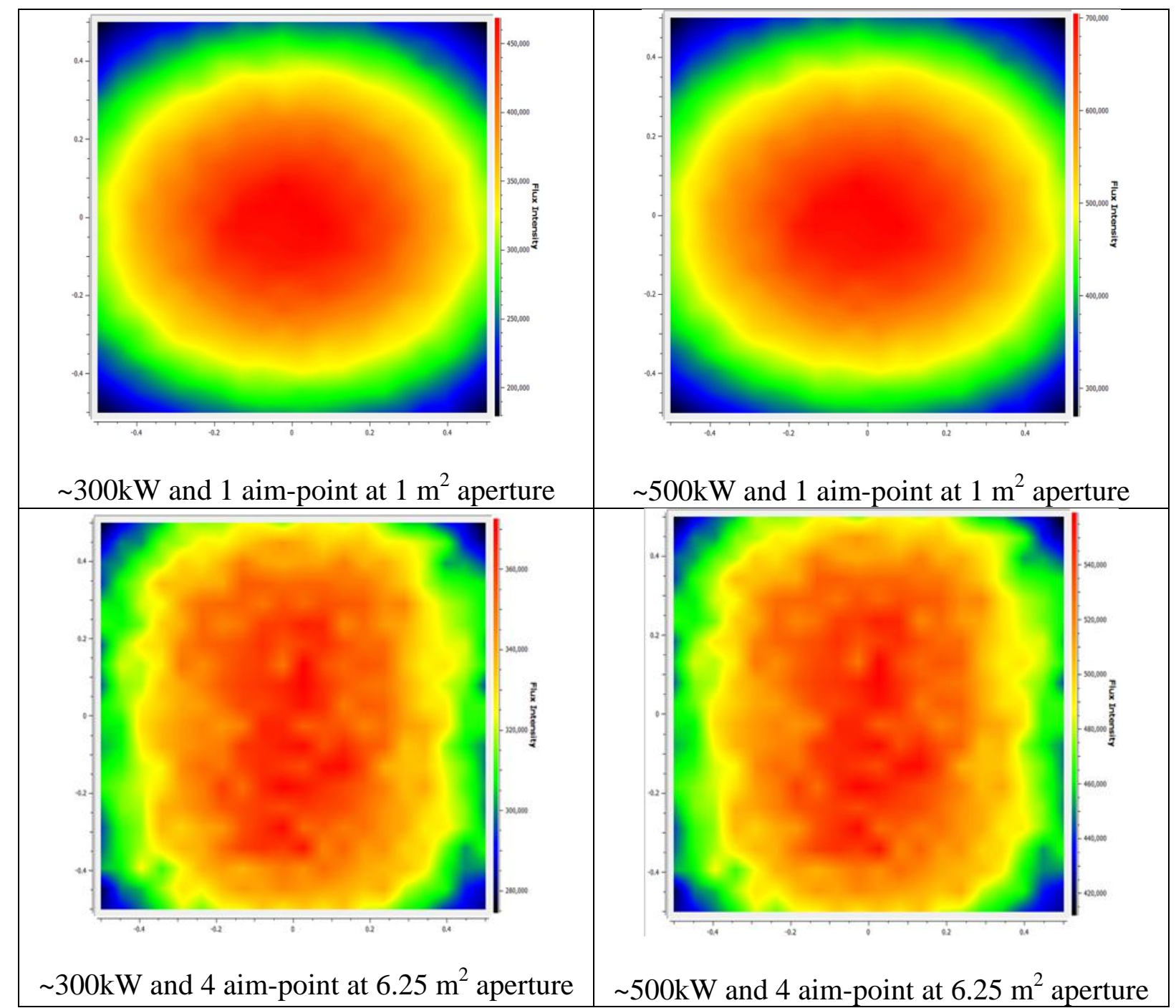
Figure 5. Heat flux distribution for two selected aim-point strategies and power levels.

2 The reflectivity of the receiver surface was specified as 0.1 for oxidized Inconel [17]. Upon

3 further investigation, the best distribution using 4 aim-points was displayed using a $2.5 \mathrm{~m} \mathrm{x}$

$42.5 \mathrm{~m}$ virtual intercept. Fig. 5 shows the results of the ray tracing with the selected heat flux

5 distributions on optical intercept of the receiver, to be used for subsequent sections of this

6 work. The optical intercept of the receiver corresponds to the projected area of the receiver

7 which is intersected by the sunrays. Fig. 6 shows the locations of the aim-points with respect

8 to the optical intercept. 

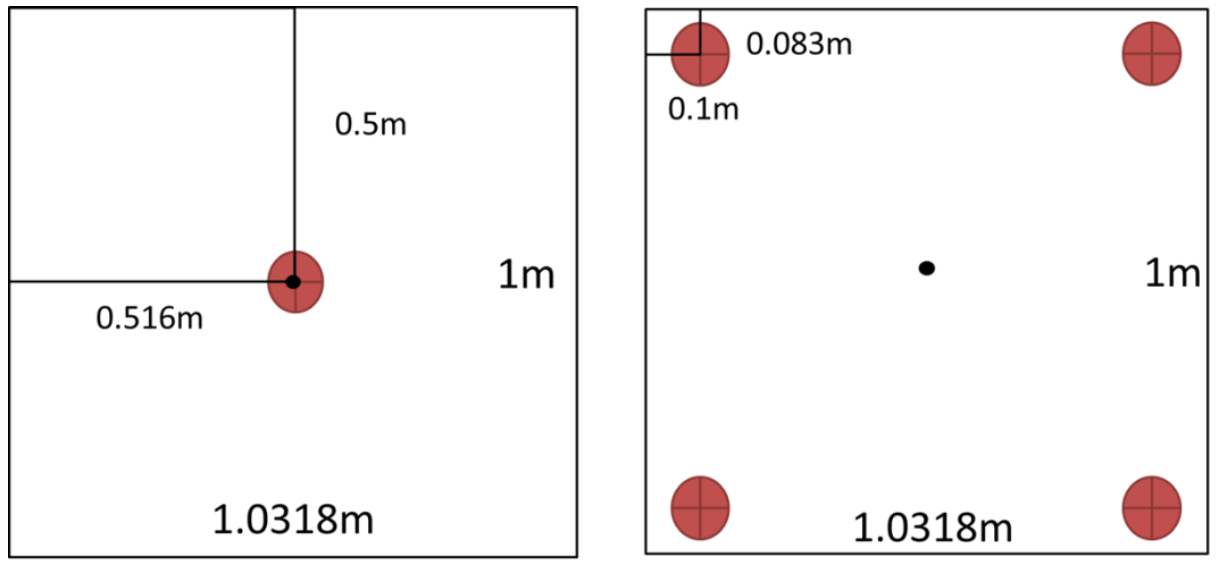

Figure 6. Single and four aim-point strategies with respect to the receiver's optical intercept.

Having established the aim-point locations using a projected, or flat, aperture area, the ray-tracing was completed using the geometries of the actual receiver tubes. These results were coupled to Fluent using the same methodology described by Ortega et al. [14].

\subsection{Computational Fluid Dynamics (CFD) Modeling}

A uniform hexahedral mesh consisting $\sim 5 \times 10^{6}$ cells was generated using ANSYS 16 Meshing, as shown in Fig. 7. The grid has two special characteristics: 1) 2 elements were used along the thickness of the tube to account for the conductive heat transfer and 2) a single inflation layer was used to model the near-wall region of the tube and fluid. The reasoning behind these two choices is described further. The equations describing mass, momentum and energy transport, and the two equation SST (Shear Stress Transport) k- $\omega$ turbulence model were solved using ANSYS Fluent 16, which uses the finite volume method to discretize the transport equations. The steady state, pressure based solver using SIMPLE algorithm and second-order upwind for spatial discretization was used for the simulation. Mass flux, energy flux and scaled residuals were continuously monitored as the solution developed, and convergence was assumed only when the quantities of interest exhibited negligible variation and the scaled residuals for all equations dropped to at least below $10^{-3}$ and remained constant thereafter. 
Wagner is used by this database [19].
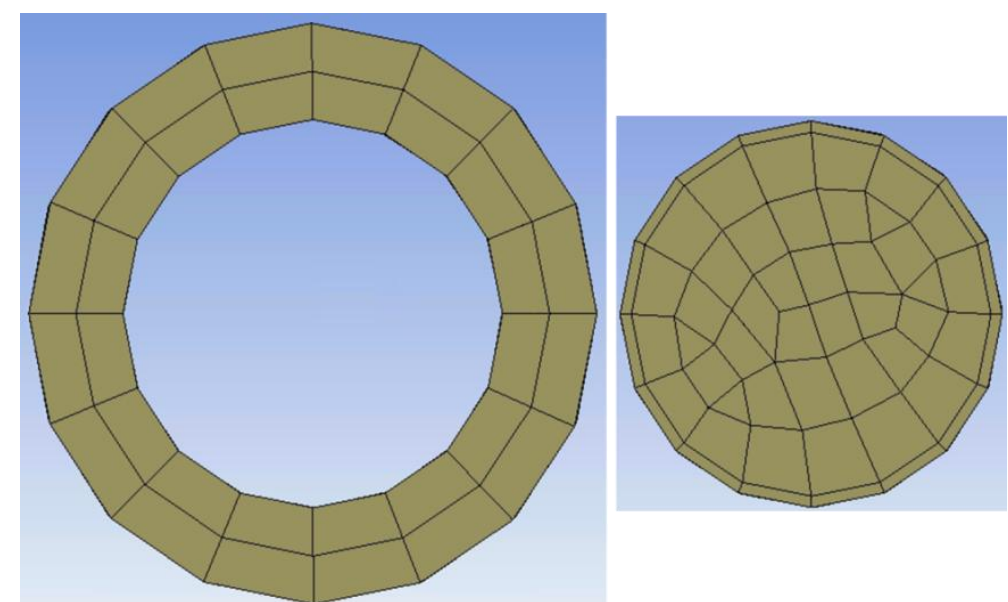

\section{Figure 7. Left: Mesh used in a single tube used for all the 80 tubes. Right: Interior mesh fluid region requires a layer which is capable of yielding the $\mathrm{Y}+$ value requirement.}

\subsubsection{Fluid Flow}

Since the receiver has several panels, different flow configurations were designed to study the possibility of enhancing the receiver efficiency. The mass flow rate for each of the flow configurations was determined under the requirement of temperature rise $\sim 160 \mathrm{~K}$ (i.e. 813 to $973 \mathrm{~K}$, approximately). Fig. 8 exemplifies the six flow configurations that were chosen to be analyzed. Since the simplified geometry was modeled, the manifolds were not included, and an equivalent recirculation boundary condition was used. Nonetheless, a flow distribution effectiveness study was performed in order to assure that the fluid flow was uniformly distributed in the manifold, and the findings are discussed in the results section. The pressure drop was investigated to ensure that the pressure change across the flow path does not substantially alter the properties of the fluid and the results are discussed in more detail in the following section. The importance of maintaining a low pressure drop is that the thermophysical properties largely become functions of temperature change only. This is important because the recirculation boundary condition in ANSYS Fluent 16 cannot be used with the density based solver, which would have been a necessity if the pressure drop was significant. 


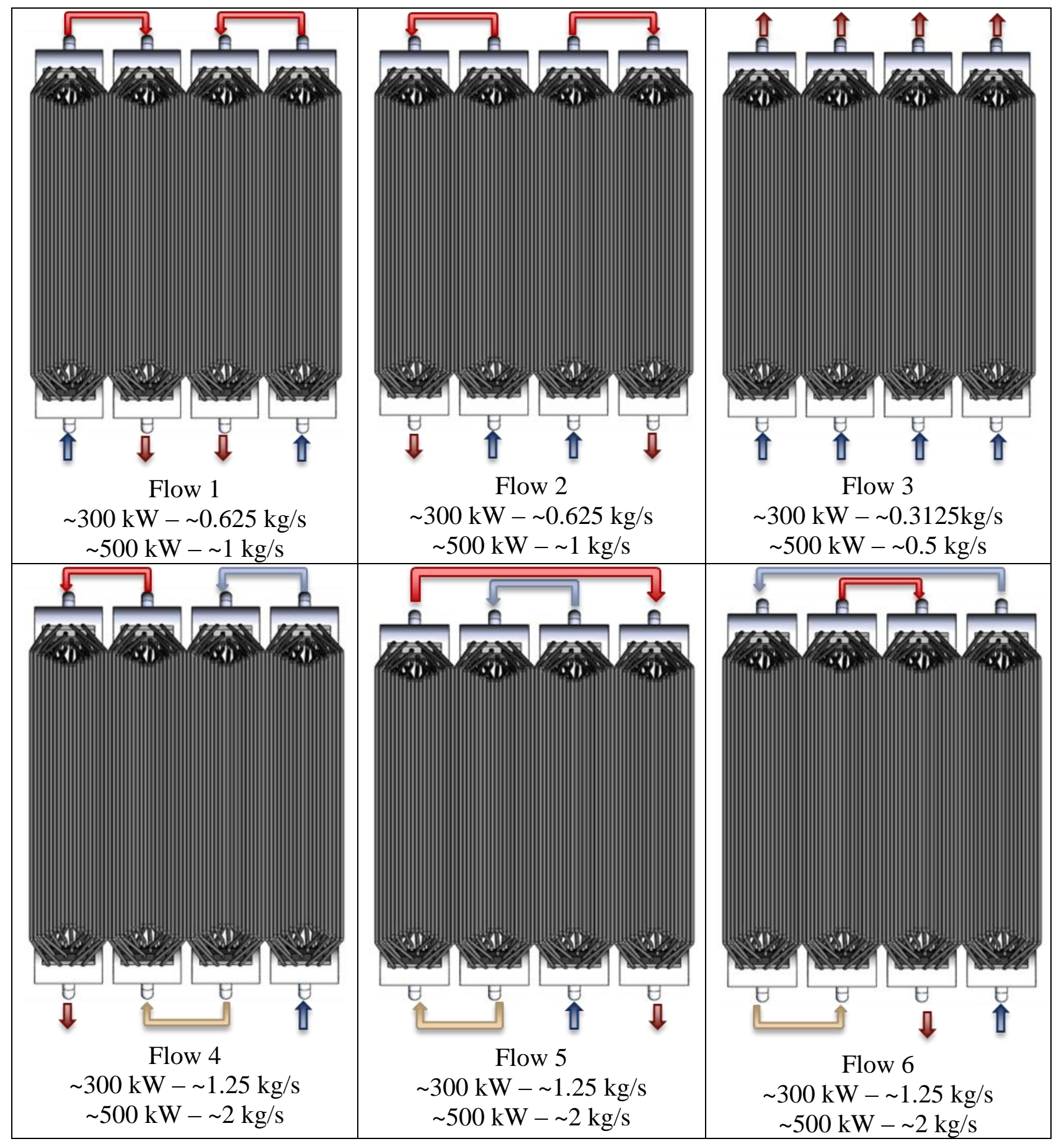

Figure 8. Flow configurations analyzed. The fluid flow goes from cold inlet (Blue) to hot outlet (Red). The approximate inflows vary depending on the power incident and the flow pattern.

The SST k- $\omega$ turbulence model is used to solve for the turbulent flow inside the tubes.

6 The model is more accurate and reliable for a wider class of flows because the wall boundary

7 conditions for the $\mathrm{k}$ equation in the $\mathrm{k}-\omega$ models are treated in the same way as the $\mathrm{k}$ equation

8 is treated when enhanced wall treatments are used with the $\mathrm{k}-\varepsilon$ models. This means that all 
boundary conditions for wall-function (coarse) meshes will correspond to the wall function approach. Since the range of $30 \leq \mathrm{Y}+\leq 300$ is so extensive, a single element inflation layer can be used as long as the $\mathrm{Y}+$ value is still inside the range.

\subsubsection{Conjugate Heat Transfer}

A gray-body model was implemented to approximate the radiative losses between the tubes and the environment. The outer walls of the tube were assumed to have a constant emissivity of 0.76 assuming oxidized Inconel. The model considers the radiative interaction between the tubes to be negligible. Two-elements on wall were sufficient to yield grid independence for thermal conduction. The inner surfaces of the tubes were assumed to have a constant emissivity of 0.76 as well. Caliot et al. show that for a turbulent flow, radiation has negligible influence on the heat transfer of s- $\mathrm{CO}_{2}[20]$. Hence $\mathrm{s}-\mathrm{CO}_{2}$ was considered as a nonparticipating medium. The convective losses only considered natural convection, by assuming a constant heat transfer coefficient of $10 \mathrm{~W} / \mathrm{m}^{2-} \mathrm{K}$ at ambient conditions.

The heat flux distribution profile obtained from the processing of SolTrace output was applied as a heat generation profile boundary condition on the heated walls of the tube. This enables the coupling of mixed thermal losses boundary condition with the internal domains consisting of tube thickness and fluid volume containing s- $\mathrm{CO}_{2}$.

\section{RESULTS AND DISCUSSIONS}

In this section, the results for flow distribution through manifolds and pressure drop through s- $\mathrm{CO}_{2}$ tubes are presented first, followed by discussion on numerically obtained receiver efficiency and temperature distribution on the irradiated surface of the tubes.

\subsubsection{Flow Distribution at the Manifolds}

As mentioned in the previous section, the panels require a set of headers that will distribute the flow into the 20 tubes connected to them. Fig. 9 shows the manifold design used for the analysis. The goal of the flow distribution was to determine the average 

simplified model suggested in Fig. 1.
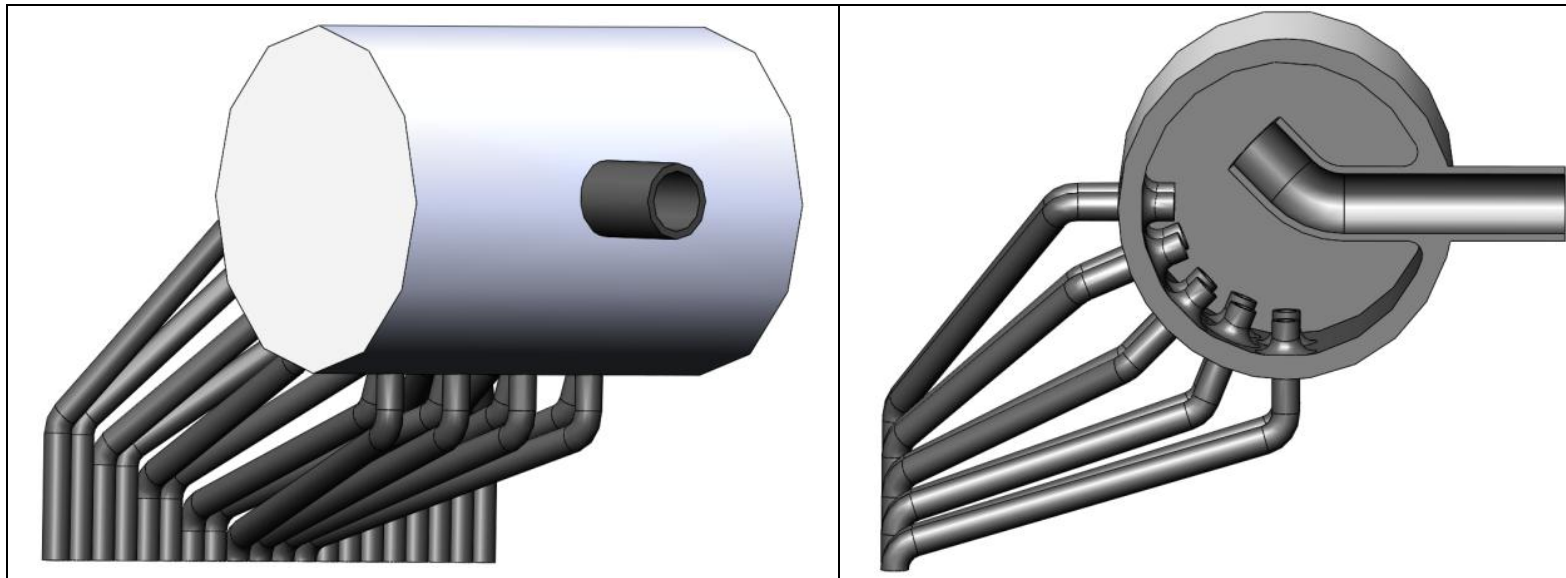

Figure 9. Manifold design used for the receiver panels. The manifold is designed assuming a $0.1524 \mathrm{~m} \mathrm{SCH} 160$ pipe. And a $0.0254 \mathrm{~m} \mathrm{SCH} 40$ pipe as an inlet or outlet connections.

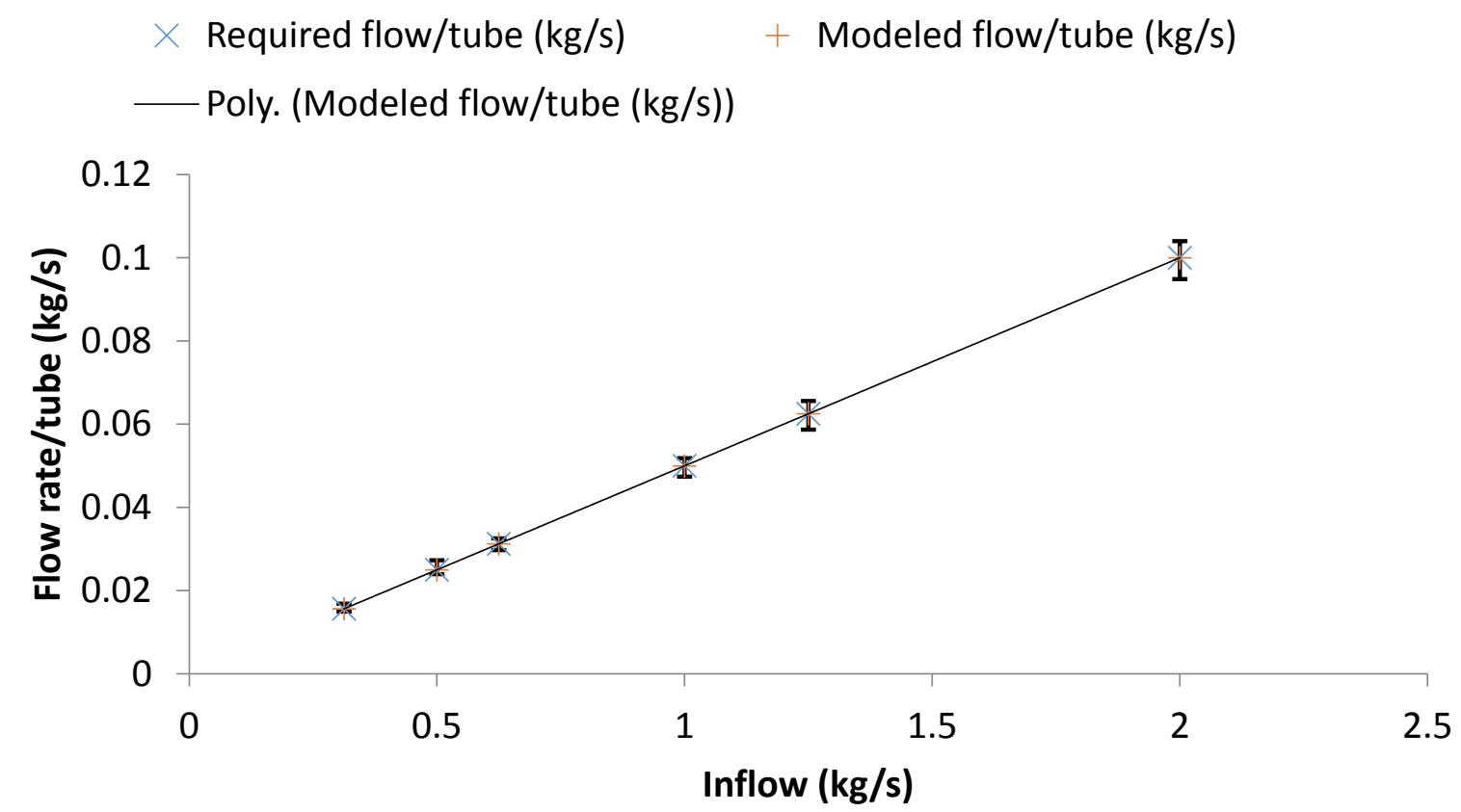

Figure 10. Flow distribution across the manifold with a single inflow and 20 outflow tubes. The error bars represent the range of flow rates along all the tubes of the panel.

Fig. 10 compares the required flow rate per tube for a given inflow mass flow rate and the modeled mass flow rate per tube. This ensures that the simplified version of the geometry 
1 required flow rate per tube is obtained by dividing the inflow mass flow rate by the number

2 of tubes attached to the panel (i.e. 20). The maximum flow range does not exceed $10 \%$ of the 3 average value for every case.

4

5

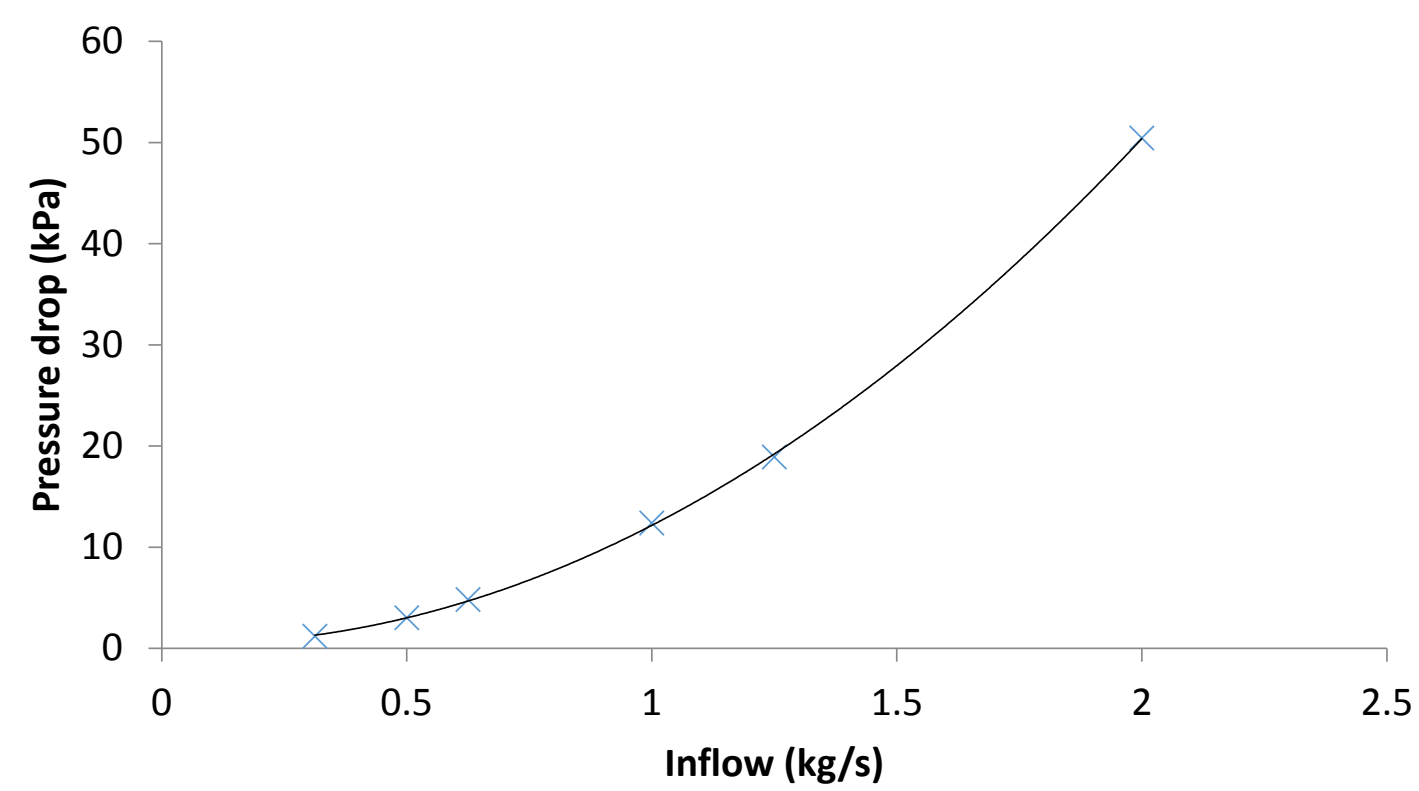




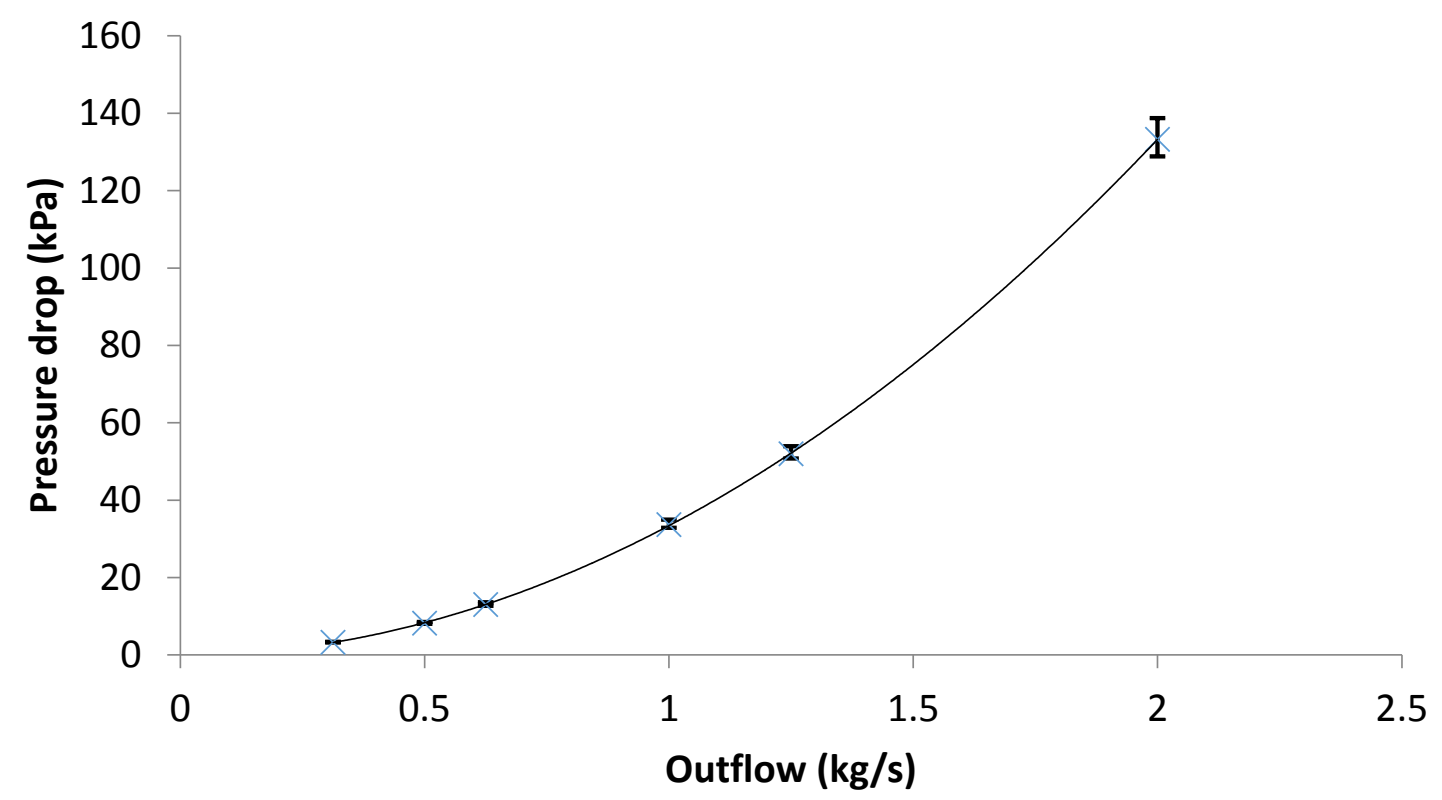

Figure 12. Pressure drop across the manifold with 20 inflow tubes and a single outflow. The error bars represent the range of pressures along all the tubes of the panel.

The frictional losses inside each tube were estimated assuming s- $\mathrm{CO}_{2}$ at its maximum expected temperature (973K). Fig. 13 shows the relationship of the pressure drop due to the

frictional losses and the mass flow rate per tube.

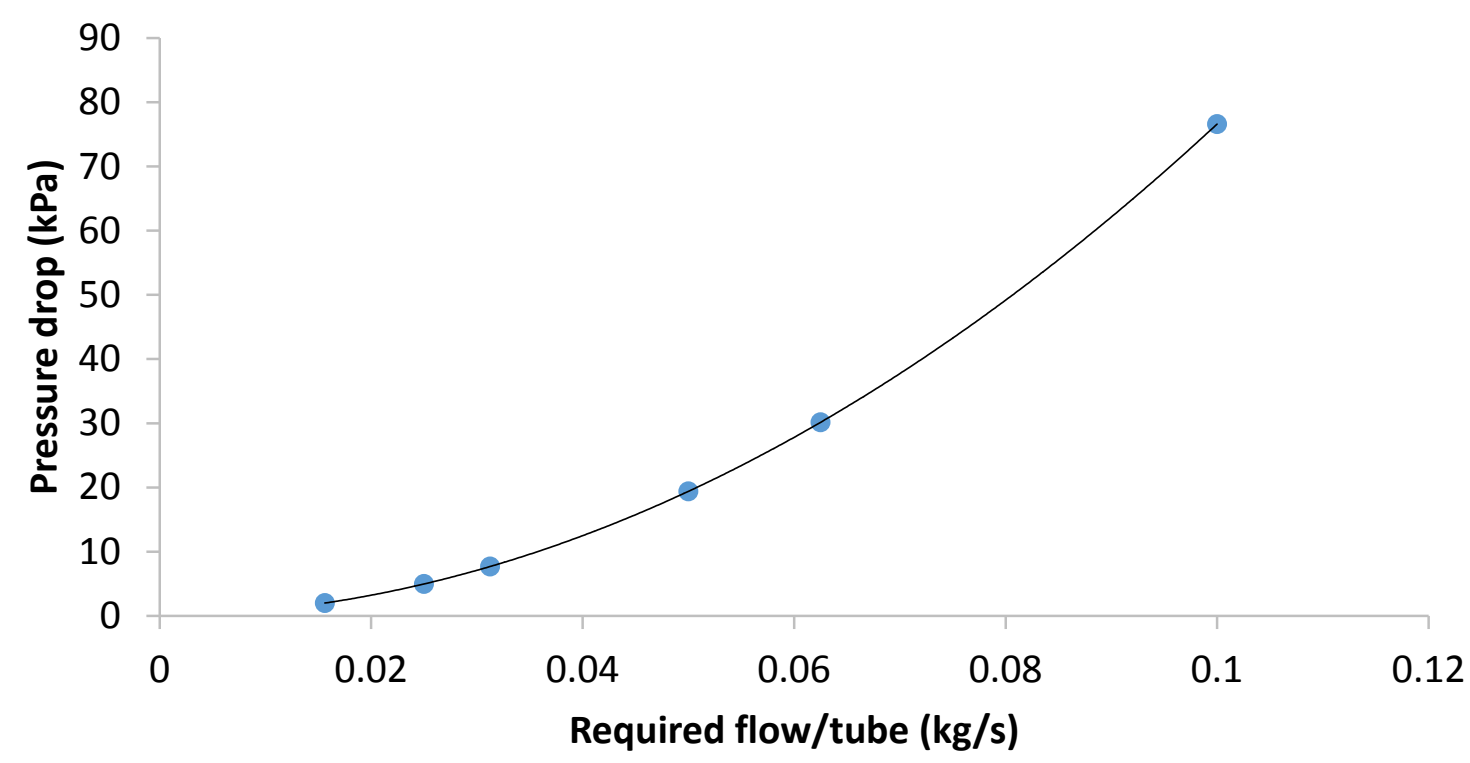

Figure 13. Pressure drop across a single tube as function of the required flow rate. The tube length is assumed $1.25 \mathrm{~m}$ and $4-90^{\circ}$ bends for the worst case scenario calculated.

The results of the pressure drop analysis provide a conservative (i.e. upper limit) 13 insight of the pressure drop across the elements of a single panel. It was observed that 
6 Where $\eta_{\text {th }}$ the thermal efficiency of the receiver, $\dot{Q}_{\text {surf }}$ is the power absorbed by the receiver 7

applying the least amount of recirculation from panel to panel yields the lowest pressure drop across the receiver.

\subsubsection{Receiver Efficiency}

The thermal efficiency calculations are performed using equation 2 .

$$
\eta_{\mathrm{th}}=\frac{\dot{Q}_{a b s}}{\dot{Q}_{\text {surf }}}
$$

surface and $\dot{Q}_{a b s}$ is the heat absorbed by the heat transfer fluid.

In turn, $\dot{Q}_{a b s}$ is defined by the difference of the power absorbed by the receiver surface and the radiative and convective losses as functions of the surface temperatures, as described in equations 3-5 as:

$$
\begin{aligned}
& \dot{Q}_{a b s}=\dot{Q}_{\text {surf }}-\dot{Q}_{\text {rad }}-\dot{Q}_{c o n v} \\
& \dot{Q}_{\text {rad }}=\varepsilon \sigma A\left(T_{\text {surf }}{ }^{4}-T_{\infty}{ }^{4}\right) \\
& \dot{Q}_{c o n v}=h A\left(T_{\text {surf }}-T_{\infty}\right)
\end{aligned}
$$

Where $\dot{Q}_{\text {rad }}$ is the heat radiated to the environment, $\dot{Q}_{c o n v}$ is the heat lost to natural convection, $\varepsilon$ is the thermal emissivity, $\sigma$ is the Stephan-Boltzmann constant, $A$ is the surface area, $h$ is the heat transfer coefficient and $\mathrm{T}$ is the temperature at the surface and environment respectively. Following equations 3-5 and using the area-weighted average wall temperatures from Fluent, the heat losses were estimated. Fig. 14 shows the thermal efficiency results; it must be noted that these values only represent the thermal losses of the receiver. 


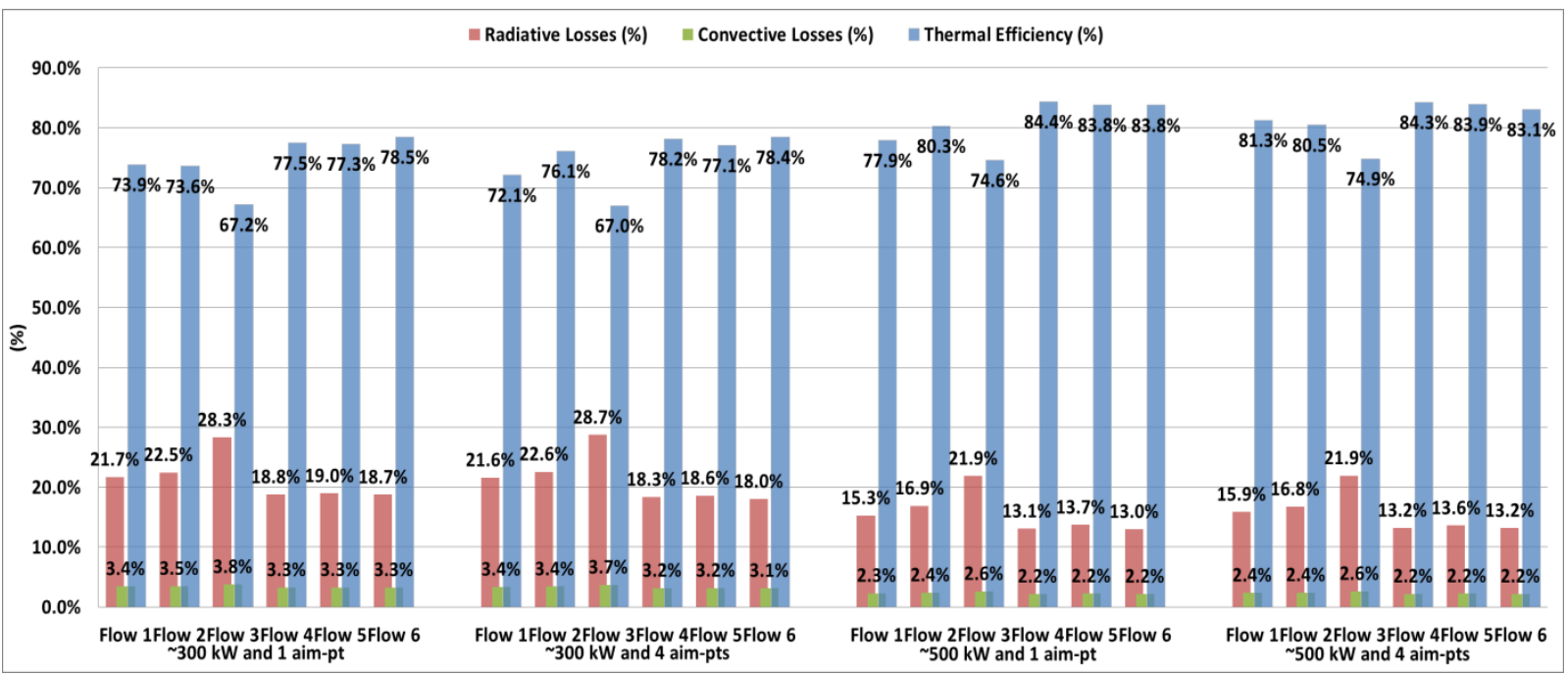

Figure 14. Receiver Thermal Efficiency

To account for the reflective losses, the thermal efficiency must be multiplied by the

optical efficiency (Equation 1) and this will yield the overall receiver efficiency (Equation 6).

Fig. 15, shows the overall receiver efficiency including the reflective losses.

$$
\eta_{\text {receiver }}=\eta_{\text {opt }} \eta_{\text {th }}
$$

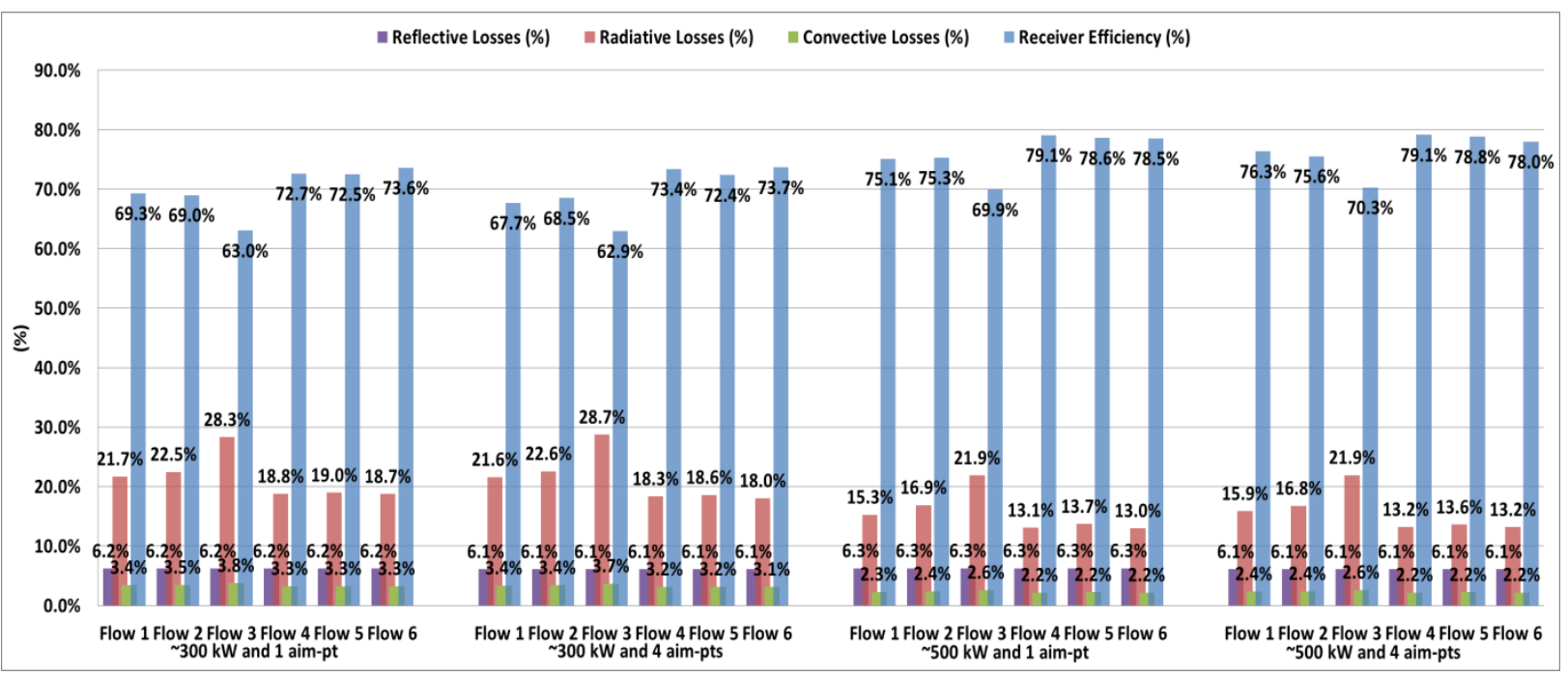

Figure 15. Receiver Overall Efficiency without considering spillage losses.

The temperature distribution along the receiver plays a very significate role in the thermal efficiency calculation. It has been observed that using recirculation flow patterns can be advantageous for the thermal efficiency of the receiver. Fig. 16 (a) and 16 (b) show the comparison of two cases where a $\sim 9 \%$ thermal efficiency increase is shown as a result of the flow conditions. 


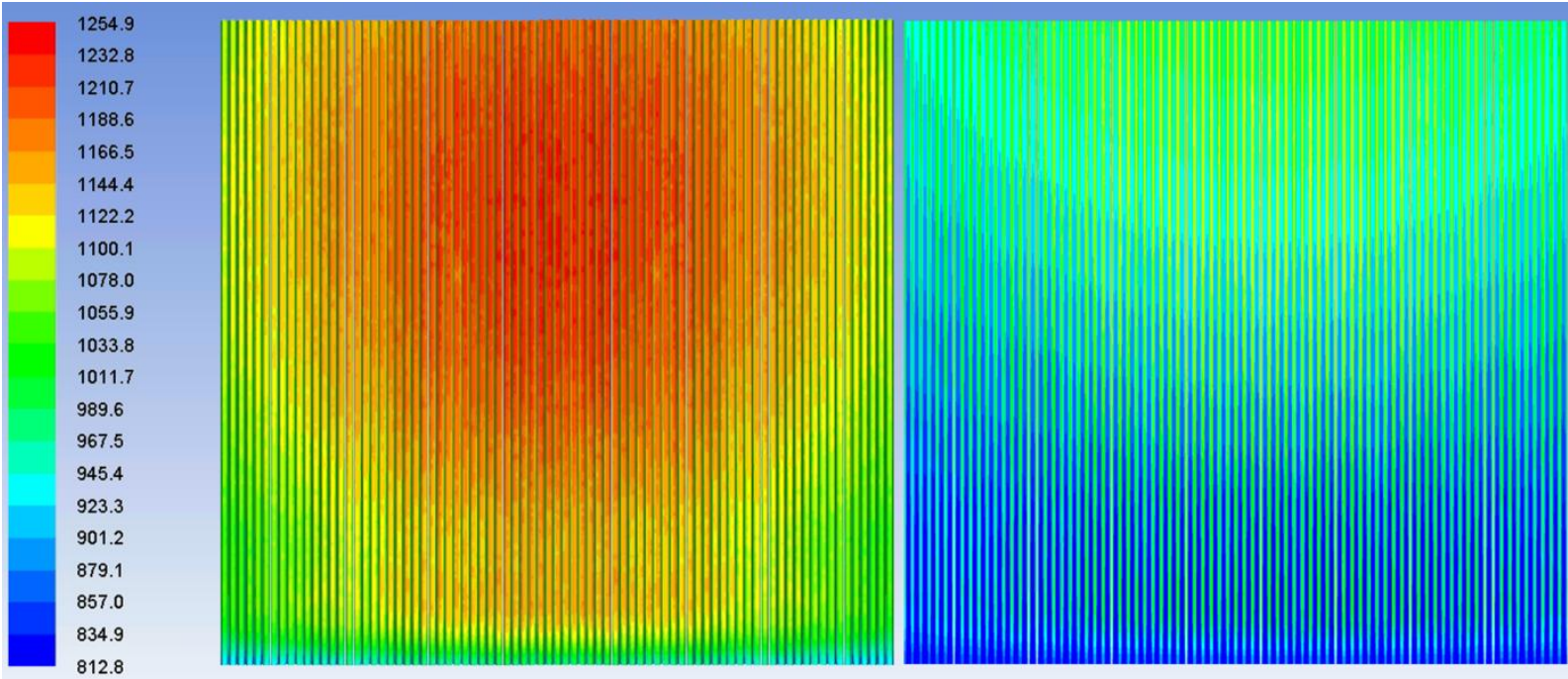

Figure 16a. Wall (left) and Center-Plane (right) Temperature Contours (in Kelvin) for Flow 3 with $\sim 500 \mathrm{~kW}$ and 4 aim-points

cases which yielded the highest pressure drop across the receiver panels. This pressure drop

was $\sim 5 \%$ for the cases in which the flow pattern had many recirculation flow passes (Flow 4-

6). A maximum pressure drop of $\sim 1 \mathrm{MPa}$ there is an estimated at the highest outlet temperature yielding a $\sim 5 \%$ reduction in density, while the reductions in heat capacity, viscosity and thermal conductivity are $\sim 0.5 \%$. Even though the change in density is significant due to the pressure change, the effect on the heat transfer coefficient inside the 
tubes is nearly negligible (about $0.1 \%$ ) for a given flow rate. The highest thermal efficiency corresponds to the cases with flow patterns that have the most recirculation. This will be due to the higher heat transfer coefficient that the flow exhibits inside the tubes when the mass flow rate is greater and the Reynolds number is higher. It is also shown that the maximum outer wall temperature is $\sim 1100 \mathrm{~K}$ for the cases with higher power input. These high temperatures are well within the operating limits of the material under consideration.

Although there is a visible difference in the enhancement of the thermal performance of the receiver which has a higher power input, the distribution of the aim-points on the receiver did not show any sign of improvement towards the thermal efficiency as shown in figures 14 and 15 . The main limitation identified is the size of the receiver which makes the distribution of a single aim-point sufficient to encompass the foot print of the receiver. Nonetheless, for a larger-scale receiver, the aiming strategy might be crucial.

\section{ACKNOWLEDGMENTS}

Sandia National Laboratories is a multi-program laboratory managed and operated by Sandia Corporation, a wholly owned subsidiary of Lockheed Martin Corporation, for the U.S. Department of Energy's National Nuclear Security Administration under contract DE-AC0494AL85000. This research is based upon work supported by the Solar Energy Research Institute for India and the U.S. (SERIIUS) funded jointly by the U.S. Department of Energy subcontract DE AC36-08G028308 (Office of Science, Office of Basic Energy Sciences, and Energy Efficiency and Renewable Energy, Solar Energy Technology Program, with support from the Office of International Affairs) and the Government of India subcontract IUSSTF/JCERDC-SERIIUS/2012 dated 22nd Nov. 2012.

\section{REFERENCES}


1. E.G. Feher, 1967, "The supercritical thermodynamic power cycle," Proceedings of the Intersociety Energy Conversion Engineering Conference, Douglas Paper No. 4348.

2. E.G. Feher, 1968, "Investigation of supercritical cycle," Astropower Laboratory, Missile \& Space Systems Division, Technical Report AFAPL-TR-68-100, AD843063.

3. V. Dostal, P. Hejzlar, M.J. Driscoll, N.E. Todreas, 2001, “A supercritical CO2 Brayton cycle for advanced reactor applications," Transactions of the American Nuclear Society 85, pp. $110-111$.

4. V. Dostal, 2004, "A supercritical carbon dioxide cycle for next generation nuclear reactors," PhD thesis, MIT-ANP-TR-100.

5. Garg, P., Kumar, P., Srinivasan, K., 2013, "Supercritical carbon dioxide Brayton cycle for concentrated solar power,” The Journal of Supercritical Fluids 76, pp 54-60.

6. Singh, R., Miller, S. A., Rowlands, A. S., Jacobs, P. A., 2013, "Dynamic characteristics of a direct-heated supercritical carbon-dioxide Brayton cycle in a solar thermal power plant," Energy 50, pp. 194-204.

7. S. D. Khivsara, Pradip Dutta, Vinod Srinivasan, R. N. Das, T.L. Thyagaraj, S. Dhar, "Development of a Ceramic Pressurized Volumetric Solar Receiver for Supercritical CO2 Brayton Cycle, " ASME 2014 8th International Conference on Energy Sustainability, Boston, MA, 29th June-2nd July, 2014

8. Ho, C. K., Iverson, B. D., 2014, "Review of high-temperature central receiver designs for concentrating solar power," Renewable and Sustainable Energy Reviews, 29, pp. $835-846$.

9. Ávila-Marin, A. L., 2011, "Volumetric receivers in solar thermal power plants with central receiver system technology: a review," Solar energy, 85(5), pp. 891-910. 
10. Becker, M., Fend, T., Hoffschmidt, B., Pitz-Paal, R., Reutter, O., Stamatov, V. Trimis, D., 2006, "Theoretical and numerical investigation of flow stability in porous materials applied as volumetric solar receivers," Solar energy, 80(10), pp. 1241-1248.

11. Kribus, A., Ries, H., Spirkl, W., 1996, "Inherent limitations of volumetric solar receivers," Journal of Solar Energy engineering, 118, pp. 151-155.

12. Dostal V., "A supercritical carbon dioxide cycle for next generation nuclear reactors," PhD Thesis, Nuclear Engineering, (2004) Massachusetts Institute of Technology.

13. Ortega, J. D., Christian, J. M., Yellowhair, J. E., Ho, C. K., "Coupled Optical-ThermalFluid Modeling of Novel Light-Trapping Tubular Panels for Concentrating Solar Power Receivers", Proceedings of the 9th International Conference on Energy Sustainability (ES2015), San Diego, CA, June $28^{\text {th }}-$ July $2^{\text {nd }} 2015$.

14. Ortega, J. D., Khivsara, S. D., Christian, J. M., Yellowhair, J. E., Ho, C. K., "Coupled Optical-Thermal-Fluid Modeling of a Directly Heated Tubular Solar Receiver for Supercritical CO2 Brayton Cycle", Proceedings of the 9th International Conference on Energy Sustainability (ES2015), San Diego, CA, June $28^{\text {th }}-$ July $2^{\text {nd }} 2015$.

15. Yellowhair, J. M., Ortega, J. D., Christian, J. M., Ho, C. K., "Solar optical codes evaluation for modeling and analyzing complex solar receiver geometries", Proceedings of SPIE Vol. 9191, 91910M (2014) SPIE Digital Library.

16. Wendelin, T., 2003, "SolTRACE: A New Optical Modeling Tool for Concentrating Solar Optics," Proceedings of the ISEC 2003: International Solar Energy Conference, 15-18 March 2003, Kohala Coast, Hawaii. New York: American Society of Mechanical Engineers, pp. 253-260; NREL Report No. CP-550-32866.

17. Ortega, J. D., Yellowhair, J. E., Ho, C. K., "Calorimetric Evaluation of Novel Concentrating Solar Receiver Geometries with Enhanced Effective Solar Absorptance", 
Proceedings of the 10th International Conference on Energy Sustainability (ES2016), San Diego, CA, June $26^{\text {th }}-30^{\text {th }} 2016$. (To be published)

18. Lemmon, E.W., Huber, M.L., McLinden, M.O., 2013, NIST Standard Reference Database 23: Reference Fluid Thermodynamic and Transport Properties-REFPROP, Version 9.1, National Institute of Standards and Technology, Standard Reference Data Program, Gaithersburg.

19. Span, R., Wagner, W., 1996, "A New Equation of State for Carbon Dioxide Covering the Fluid Region from the Triple-Point Temperature to $1100 \mathrm{~K}$ at Pressures up to 800 MPa,” J. Phys. Chem. Ref. Data, 25(6), pp. 1509-1596.

20. C. Caliot, G. Flamant, "Pressurized Carbon Dioxide as Heat Transfer Fluid: Influence of Radiation on Turbulent Flow Characteristics in Pipe" AIMS Vol. 2, Issue 2, 2014, pp.172-182.

\section{Nomenclature}

$\eta_{\text {opt }} \quad$ optical efficiency of the receiver

$\dot{Q}_{\text {surf }} \quad$ power absorbed by the receiver surface (W)

$\dot{Q}_{\text {in }} \quad$ incident power on the receiver surface (W)

n number of aim points

k turbulent kinetic energy (J)

$\omega \quad$ specific turbulence dissipation (/s)

$\mathrm{Y}+\quad$ non-dimensional cell height

$\varepsilon \quad$ turbulence dissipation $(\mathrm{J} / \mathrm{kg}-\mathrm{s})$

$\eta_{\text {th }} \quad$ thermal efficiency of the receiver

$\dot{Q}_{a b s} \quad$ power absorbed by the fluid (W)

$\dot{Q}_{\text {rad }} \quad$ power lost to atmosphere by radiation (W)

$\sigma \quad$ Stefan-Boltzmann's constant $\left(\mathrm{W} / \mathrm{m}^{2}-\mathrm{K}^{4}\right)$

A Total area of tube surface $\left(\mathrm{m}^{2}\right)$

$T_{\text {surf }} \quad$ Tube surface temperature (K) 
Coupled Modeling of a Directly Heated Tubular Solar Receiver for Supercritical Carbon Dioxide Brayton Cycle: Optical and Thermal-Fluid Evaluation

$1 \quad T_{\infty} \quad$ Average ambient temperature $(\mathrm{K})$

$\dot{Q}_{\text {conv }} \quad$ power lost to atmosphere by convection (W)

$h \quad$ convection heat transfer coefficient $\left(\mathrm{W} / \mathrm{m}^{2}-\mathrm{K}\right)$

4 